\title{
A Case Study of King's Science Operational Factors in the Sufficiency School
}

\author{
Phuwadon Chulasukhont ${ }^{*}$, Poggade Chulasukhont \\ Faculty of Education, Thepsatri Rajabhat University, Thailand
}

Received March 26, 2020; Revised April 23, 2020; Accepted May 3, 2020

Copyright@2020 by authors, all rights reserved. Authors agree that this article remains permanently open access under the terms of the Creative Commons Attribution License 4.0 International License

\begin{abstract}
King Bhumibol's science known as sufficiency economy philosophy encourages Thai citizens to live based on themselves, and all schools have been teaching their students to cultivate, learn and practice this sustainable theory. The objectives of this research were to 1) study the King's Science operational factors in the sufficiency school under the Lop Buri Primary Educational Service Area Office, and 2) create the model of the operation according to the King's Science of the sufficiency schools. The research sample was consisted of 321 school administrators and teachers by implementing the Yamane technique to stratify random sampling. The research instruments were questionnaire and structured interview form with a reliability of 0.87 . The data were analyzed by using percentage, mean, standard deviation, and content analysis. The research results showed that 1) the King's Science operational factors in the sufficiency school were rated overall at a high level. They were arranged in descending order of their mean values as follows: accomplishment aspects, administration aspects, and activity of student development aspects, and 2) the model of the operation according to the king's science by the case study of sufficiency school was possible, useful, consistent, and suitable for the context. This model also had been approved by the participants of focus group discussion and could be used as a practical guideline for schools in Lop Buri.
\end{abstract}

Keywords The King's Science, Sufficiency Economy Philosophy, Sufficiency School

\section{Introduction}

From the royal speech of His Majesty King Bhumibol Adulyadej, it was said "The national development was necessary to be done in a hierarchy, beginning from creating a foundation of the people to live by using economical methods sustainably under the correct principles and stable. Then gradually build up the prosperity and economic status at the next level, if focus only on quickly creating the prosperity of economic status raising, by not focusing on the imbalances in various matters which may eventually become a failure.” In accordance with the principle of work and royal ethics of His Majesty throughout the 70 years, Thai people have adopted an excellent example into their lives. This philosophy has been applied by the government and civil servants to the public administration to create the nation and develop the country as well. [16] From "The sufficiency economy theory" to "The King's Science", through studying and practicing, it leads to the creation of a sustainable life with virtue, recognition and distinguishing various information, that can enhance the self-reliance of people.

The theory has been integrated into Thai education to encourage the learning of students sustainably. According to the long-term 20 years nation strategy, it aimed to develop and enhance the human potential that focused on life-long learning and development to become the desirable characteristic person. [24] Referring to the core curriculum of basic education, the desirable characteristics were determined in the fifth item from 8 items which was economical life. This was the reason all schools performed an essential role in cultivating the theory for students. One of the processes in terms of propelling the philosophy was integrated into teaching and school administration in order to step into sufficiency school [11].

Based on this information, the researchers who were lecturers in the Faculty of Education of Thepsatri Rajabhat University have followed the missions of the university: producing and developing teachers, including local development to establish the quality of life and learning society both internal and external education organizations to promote the sustainable society. The missions and the responsibilities triggered to the study of the King's Science operational factors into the sufficiency school, and it will 
benefit schools or educational organizations to utilize the results of this research as a practical guideline to be the sufficiency school.

\section{Literature Review}

\section{The King's Science}

The King's Science was defined as the methodology on how to induce the concept and speech of King Rama IX to set as a guideline in the daily life of Thai people. One of the development goals of his speech and concept was sustainable development. The purposes aimed to improve the people' lives, make them happy without destroying the environment, and consider the contexts of geography, religious beliefs, ethnicities, and socioeconomic backgrounds. Although the development methods were diverse, the importance was conducting with love, care, responsibility, and respect for fellow humans. The development thus involves humanity and a matter of mind [13].

Furthermore, The King's Science also was identified as the science of self-possession, in order to be good role models and the peaceful coexistence in society [26]. This science contributed Thai people to more happiness with morality and sufficiency in the world of transformation. The teachings of royal sciences are not only discourses but also benefits if one implements them seriously. Although King Rama IX passed away, his teachings should be continued. The King's Science should be inserted into educational institutions at all levels to cultivate students [25].

\section{Sufficiency Economy Philosophy}

In a royal speech by King Rama IX “...national development needs to be done in the hierarchy. The basic was begun from adequacy, the sufficiency of most people by using methods and equipment that are economical but technically correct. When having sufficient basic security and already practiced, then gradually build, enhance prosperity and a higher level of economic status...”. His speech conveyed the concept of sufficiency economy on 18 July 1974. The sufficiency economy is a philosophy based on the middle path that guides the way of existence and practice of Thai people from the family level to the state level, ready to manage the effects of both external and internal changes, which required knowledge, prudence, and caution of the planning and implementation in every step. The sufficiency economy was not just economized but also a balanced and sustainable lifestyle to survive even in the high competition of the globalized world [2].

The sufficiency economy philosophy was comprised of three aspects, including 1) Modesty was moderation that was neither too less nor too much and did not take advantage of oneself and others. 2) Reasonable was termed as the method of decision belonging to the level of sufficiency by considering the relevant factors and reasons, as well as carefully considering the expected results of such actions. 3) Immunity was the preparation to be affected by the possibility of various changes with conditions of decisions and operation of activities to be at a sufficient level. From these three elements of the philosophy above, they will be operated under two conditions. 1) The condition of knowledge consists of knowledge about various related academic and prudence to bring the knowledge into consideration and linked together with planning and careful implementation. 2) The condition of morals consisted of awareness, honesty, endurance, and perseverance and using wisdom in living [2].

\section{Sufficiency School}

Sufficiency school was the school that induced the concept of sufficiency economy philosophy to be the process of the whole-school administration approach, including the development of school personnel to be a role model for sufficient life as the principle of working and cultivating the values nurtured the sufficiency characteristics into the students. It also required an appropriate environment that was conducive to learning, both physically cultural coexistence of society and good example of the practice [28].

The Office of the Basic Education Commission is a department under the Ministry of Education. It is responsible for providing basic education, recognizing the importance of developing the critical thinking processes of the students and also cultivating the lifestyle according to the principle of sufficiency economy philosophy. Therefore, it has set the important focus to cultivate morality, awareness of being Thai, and how to live under the sufficiency life. In order to be a framework for the departments and educational institutions to use as the guideline to drive this philosophy to the schools, a clearly monitoring system for operations should be managed. In addition, the Ministry of Education has policies to propel the sufficiency economy philosophy to the educational institutions at all levels by enabling administrators, teachers, educational personnel and students to understand the principle of philosophy. What's more, the concept of sufficiency economy should be integrated into the school administration, instruction management, as well as application in the daily life sustainably [12].

\section{Objectives}

1) Study the King's Science operational factors in the sufficiency school under the Lop Buri Primary Educational Service Area Office. This first objective was focused on the study of the five success factors of sufficiency school, from the framework of indicators related to sufficiency schools' 
operation [12]. The data from this purpose will show how much of each factor affected the operation.

2) Create the model of the operation according to the king's science of the sufficiency schools under the Lop Buri Primary Educational Service Area Office. This objective was focused on the collection of data in the first process to create the model of the operation, then invited the school personnel to discuss and approve the possibility of the model from their experience. Finally, this model can be a practical guideline for the sufficiency schools in Lop Buri.

\section{Limitation}

The research samples of the first phase were 321 school administrators and teachers of the schools in Lop Buri province, Thailand. They were randomly selected by utilizing Yamane's technique [27]from the 1632 population size. In the second phase, the information was gathered by the in-depth interview method from 6 school administrators and 6 teachers from 6 schools. Then the last step, the data were collected from 8 educators who confirmed the suitability of the model.

The instruments of this research were 1) the questionnaire related to the factors affecting the conduction of the king's science of the sufficiency schools and 2) the structured interview of the king's science conduction of the sufficiency schools.

Variables under the study consisted of the five aspects from the framework of indicators related to sufficiency schools' operation, [12] obtained through the analyzing process from the study principle of the conduction according to the King's Science of the sufficiency schools. The variables were comprised of administration aspects, curriculum aspects, activity of student development aspects, activity of personnel development aspects, and accomplishment aspects. The following figure 1 shows how the model of sufficiency schools' conduction was analyzed.

\section{Methodology}

This research process was divided into two phases;

Phase I: Study the King's Science operational factors into the sufficiency school.

The methodology of this phase was initiated from studying and reviewing the literature or related research of King's Science and the sufficiency school. Then, the researcher designed and created the questionnaire and the structured interview form. After that, the instruments were investigated the suitability by five experts; three experts of the King's Science and sufficiency schools and two experts of evaluation and research methodology. The reliability of the instrument was 0.87 .

The questionnaire was employed to collect data from the school administrators and teachers who were samples. Then the data were statistically analyzed by using percentage, mean, and standard deviation. In addition, the interview was utilized to gather the data from six school administrators and six teachers who worked in the Lop Buri Primary Educational Service Area Office. The data of this process were analyzed by using content analysis.

Phase II: Create the model of the operation according to the King's science of the sufficiency schools.

This phase began from compiling the results of the first phase into the model draft and creating the model draft of conduction according to the King's science of the sufficiency schools. Then, the focus group discussion was organized by inviting eight participants, including four school administrators as policymakers and four teachers as the practitioner, to consider the appropriateness, possibility, and benefits of the draft.

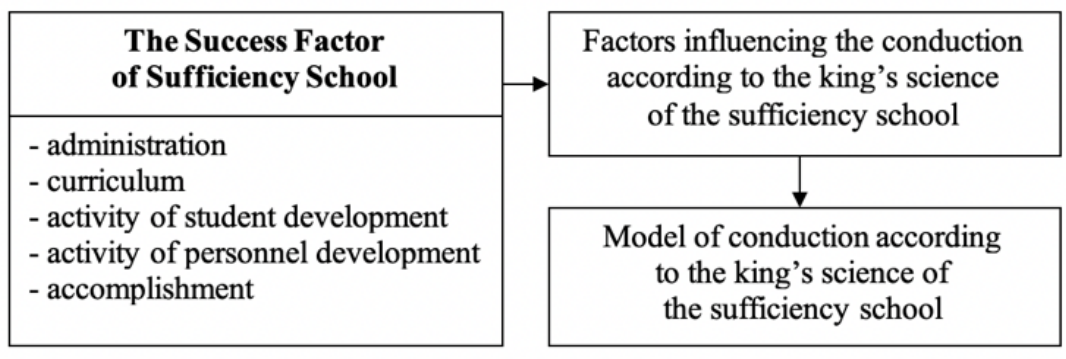

Figure 1. The conceptual of model acquisition 
The data of the focus group discussion were analyzed by using content analysis. Then the model of conduction was reformed regarding the suggestions from the focus group participants. With the expectation, the model will be suitable for the context and can be used as a practical guideline for the sufficiency schools in Lop Buri. Finally, the documents were compiled and published respectively.

\section{Results}

The results from studying the Study the King's Science operational factors into the sufficiency school were divided into two sections as follows.

Section 1: The data from the questionnaire revealed that most of the respondents were female as 78.20 percent, and 92.20 percent was classified as teachers as well as 46.70 percent of academic standing. The working experiences were between 10-20 years as 35.20 percent. 54.50 percent of all respondents were working in medium-size schools.

The King's Science operational factors into the sufficiency school were rated overall at a high level $(\overline{\mathrm{x}}=$ 4.11 , S.D. $=0.46)$. They were arranged in descending order of their mean values as follows: accomplishment aspects $(\overline{\mathrm{x}}$ $=4.20$, S.D. $=0.57)$, administration aspects $(\overline{\mathrm{x}}=4.18$, S.D. $=0.54)$, and activity of student development aspects $(\overline{\mathrm{x}}=$ 4.14, S.D. $=0.54)$. The curriculum aspects were at the least significant factor. $(\bar{x}=4.01$, S.D. $=0.58)$, as shown in the following table 1 .

Section 2: The structured interviewed data from school administrators and teachers.

The data of the sufficiency school operations from the interview of school administrators revealed that the beginning process to propel the school according to the sufficiency economy philosophy should begin from creating the understanding and knowledge of philosophy into all personnel in the school to operating in the same direction. In terms of operations, it was found that the school administrators should behave themselves in accordance with the principles of sufficiency because it can increase more confidence of the personnel to follow the behavior. Furthermore, as for the monitoring, there is additional information that school administrators should allocate time to closely monitor on this matter process and encourage the continuous and serious operation.

The data of the sufficiency school operations from the interview of teachers discovered that before the proceeding, the school should organize a meeting to make all teachers understand in the same direction. In addition, the administrators of the schools were expected by the teachers to perform as role models regarding sufficiency guidelines. In the matter of setting the target, it was found that all teachers should mutually set the target clearly, and also get more information of the implementation of the project in some activities. Then each of the nearby schools can cooperate to enhance more efficiency.

From the data mentioned above, four main processes can be summarized separately below.

1) Created understanding; This process will help everyone involved understand each other, increase the good attitude together and be able to work in the same direction with more efficiency.

2) Behaved as an example; In this process, the school administrators and teachers should behave as the example behavior of sufficiency since it can increase credibility and all tasks can be completed by beginning with oneself first.

3) Performance evaluation; This step is also very important because it will let all personnel in the school know how successful of the operation is, so the criteria or the performance indicators for each project or activity need to be specified.

4) Coordination; It's a collaboration process, to exchange and to learn from each other including learning to reduce the weaknesses and promoting the strengths of different contexts from each school to jointly work.

Table 1. Mean and standard deviation of The King's Science operational factors into the sufficiency school

\begin{tabular}{|c|l|c|c|c|}
\hline \multirow{2}{*}{ No. } & \multirow{2}{*}{$\begin{array}{c}\text { The conduction according to the king's science } \\
\text { of the sufficiency schools }\end{array}$} & \multicolumn{3}{|c|}{ Influenced Level } \\
\cline { 3 - 5 } & & $\overline{\mathrm{x}}$ & S.D. & Interpreted \\
\hline 1 & Administration Aspects & 4.18 & 0.54 & High \\
2 & Curriculum Aspects & 4.01 & 0.58 & High \\
3 & Activity of student development Aspects & 4.14 & 0.54 & High \\
4 & Activity of personnel development Aspects & 4.03 & 0.61 & High \\
5 & Accomplishment Aspects & 4.20 & 0.57 & High \\
\hline & Overall & 4.11 & 0.46 & High \\
\hline
\end{tabular}


The results from the model of the operation according to the King's science of the sufficiency schools showed that after finishing focus group discussion, the participants have approved the draft of the model and the details were improved in congruence with the recommendations as follows.

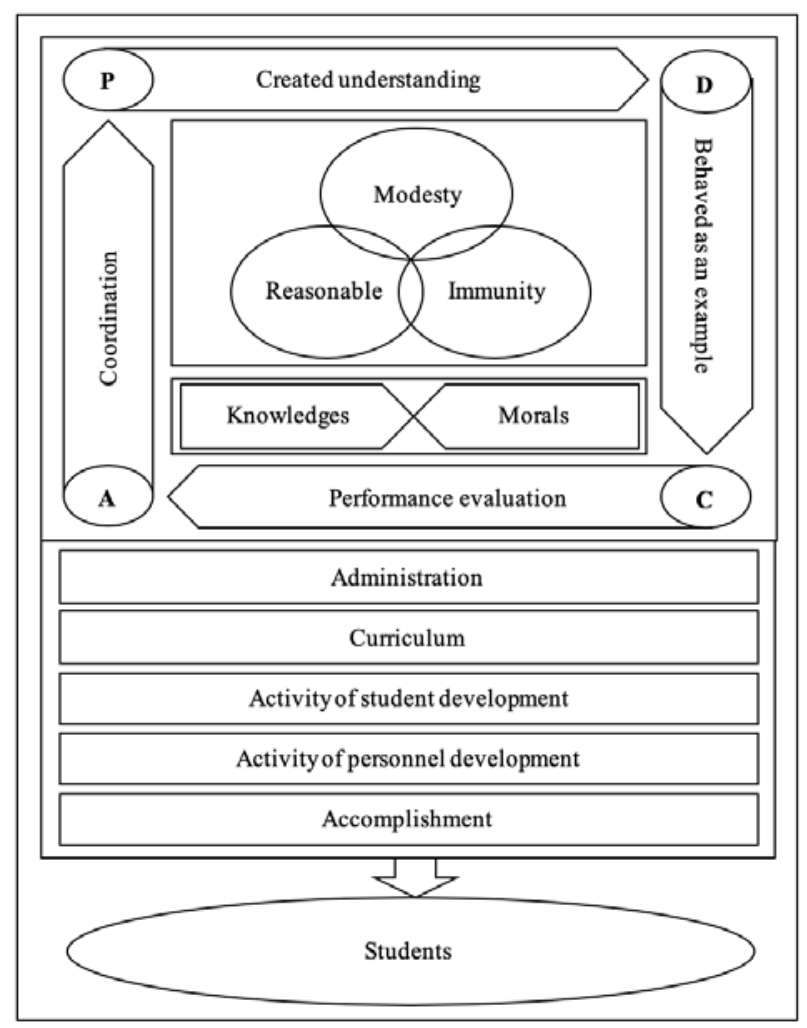

Figure 2. The model of the operation according to the king's science into the sufficiency schools

1. The operations of schools were based on the sufficiency economy philosophy, consisted of three cores including modesty, reasonable, and immunity.

1.1 Modesty meant how to conducting or living with moderation, not too much or too least, without encroaching others, and also focused on the middle path.

1.2 Reasonable meant making a decision under the reasons, considering the consequences of actions, using reasons based on sufficiency according to the principles of academics, morals, ethics and cultures, not taking into account of the desire or personal greed.

1.3 Immunity meant the understanding and the preparation to be affected by the changes in economy, society, environment, and culture and to be able to adapt and respond to those situations immediately with precaution.

2. The operation of schools in the sufficiency economy philosophy was based on two conditions including knowledge and morals.

2.1 Condition of knowledge was termed the various attainments concerning oneself for making the decisions correctly, by focusing mainly on the wisdom to enhance the conduction under the three cores more efficiently.

2.2 Condition of moral meant adhering to the morals of the living, honesty, no greediness, apportion with others, unity, endurance, and service mind.

3. The above operational process will be driven by the quality management cycle known as PDCA [5], which was the essential of the operation and continuous improvement, consisting of:

3.1 (P) Plan, this operation will begin from the school administrator creating an understanding of the sufficiency school's main idea to the personnel, together with planning of the operation, and focusing on the benefits that school will receive mainly.

3.2 (D) Do, implementation of the plan according to this process to drive the activities or projects relating the planning process which allow all personnel to establish together, the leader of each section must perform to be the example in all cases, for example the school administrators behave as role models towards the teachers, and the teachers behave as role models for the students.

3.3 (C) Check, referring to this model, this process was from mutually monitoring activities or projects in each own responsibility, then the performance was together evaluated based on the operating plans which were accordingly set as the regulator in order to reach the goals and objectives as much as possible.

3.4 (A) Act, operational improvement of this process was the continuous step. After finishing the operational evaluation, the problems, obstacles or the points needed to be improved were found out. The improvement based on the coordination from all sectors will bring about the better development in the future.

4. The operational process based on the sufficiency economy philosophy under the drive of quality management cycle (PDCA) must be applied, blended, and implemented into the five operation aspects, namely administration aspects, curriculum aspects, activity of student development aspects, activity of personnel development aspects, and accomplishment aspects.

4.1 Administration aspects, these were considered as the process that propelled all methods in the system. The information compiled by the researcher has been identified and emphasized on the application of the sufficiency economy philosophy. Besides, the information should be integrated into the annual action plans along with the project planning and activities which lead to the integration of the sufficiency economy philosophy into the teaching and learning.

4.2 Curriculum aspects were another crucial element. They can be the way to apply the sufficiency economy philosophy to the teaching and learning method. The data collected shown that the integrated learning management plan should be focused by applying the sufficiency economy philosophy into the various learning groups and all education levels. What's more, the opportunities for learners to participate in the teaching and learning activities with the integration of the sufficiency economy philosophy should be provided.

4.3 Activity of student development aspects were a continuous element from the curriculum. These were the 
channels and methods to spark the sufficiency economy philosophy to the learners, for instance the activities of Boy Scout, Red Cross or practitioner activities under the philosophy of sufficiency economy, and also the emphasis on service mind in the students by hosting the activities that supported them to participate in social and public benefits activities.

4.4 Activity of personnel development aspects were a propulsion mechanism that can create the understanding of personnel correctly in the same direction. The issue of the personnel development projects should be emphasized to establish knowledge and understanding and realize the value of sufficiency economy philosophy. In addition, the school personnel should be encouraged to study the knowledge of the sufficiency economy philosophy regularly.

4.5 Accomplishment aspects were the image of the operation or during operation which was the indication of the chance to succeed. Having been accumulated and analyzed systematically, the data unveiled that the school activities related to the sufficiency economy philosophy should be involved how to promote, support or join the activities. Furthermore, the personnel in the school must be continuously studying and developing themselves concerning this philosophy.

From the four elements mentioned above, the researcher compiled the data from the questionnaire and the interview until becoming the model of the operation according to the King's Science into the sufficiency schools. The schools should continuously be operated under the quality management cycle (PDCA) as the driven core based on the principles of creation of understanding, coordination, example behaviors, and performance evaluation. Finally all of the operations will create the self-sufficiency characteristics cultivated into the students, which can be considered as the truly sufficiency school.

\section{Discussion and Conclusions}

1. The King's Science operational factors into the sufficiency school were rated overall at a high level and the most influential factor was accomplishment aspects. It might because the success was depended on the promotion, development, and creation sustainably. In accordance with the study of Phatanasiri [14], the guidelines for school administration according to the sufficiency economy philosophy of schools in Nakhon Sawan Province showed that the success aspects were at a high level because of the organizing of activities to promote students characteristics that are useful in daily life. And also it is consistent with the study on the factors affecting the success of school management according to the sufficiency economy philosophy of the basic education school [21]. The results unveiled that one of the factors affecting success was the school factor, combining with the organization culture, the organization atmosphere, the organization structure, and the community participation. In accordance with the study of Chansila and Wansri [3], it found out that the community participation factors and organizational culture factors affect the learning management of the sufficiency economy philosophy's learning center in the northern region, by creating the values of sufficiency living and also self-improvement both inside and outside the school, including the relationships building with communities. These matters can enhance the implementation of the sufficiency economy philosophy successfully.

The administration aspects also were rated at a high level. The possibility was because the school received the policy of the sufficiency economy philosophy from the educational service area office, so it was necessary to bring this process into the practice. It is consistent with the study of Sairoj and Boonrod [20]. It obviously discovered that the schools operated according to the annual policies and the action plans to bring sufficiency economy philosophy into the school operation, result in the systematic and parallel with the management and also integrated this philosophy into the teaching and learning. In accordance with the study of Chansila and Wansri [3], the study showed that the schools operated by using the sufficiency economy philosophy to integrate into the teaching and learning management were rated at a high level. While the teachers and school administrators were the critical mechanisms in designing, planning, and operating activities, to promote the principles of the sufficiency economy into teaching and learning. In the section of financial management according to Saechan and Tangdamnernsawat [19] that studied the school administration according to the sufficiency economy philosophy in schools under the office of secondary educational service area 1 Bangkok, the results disclosed the school had followed up the operation regarding the financial plan of the school under the sufficiency economy philosophy, and reported the results of the financial usage to the stakeholder. The disbursement of financial and resources was appropriated with honesty which was clarified as being able to check the disbursement of all activities. This reflected that the school had the financial management plan, in accordance with the sufficiency economy philosophy.

The activity of student development aspects were rated at a high level. It would be because the creating concepts and cultivating the good traits of students were not only theoretical knowledge learning but productive practice, from which the students will learn from experiences. It can change the student experience better [22]. In accordance with the research of Chaimee [1], the study investigated the effectiveness of management strategies in the sufficiency school. The research found that focusing on providing the variety of activity for students can enhance the operation of sufficiency school efficiency. In addition, the school environment with the good relationships among administrators, teachers, and students was able to increase the behavior of sufficiency[6].

2. The data from the interview towards the school administrators and teachers had given in the same direction that the operation should begin with creating understanding 
for all school personnel. In addition, school administrators and teachers must behave as an example of sufficiency, specify the clear criteria for assessing activities or projects and require coordination from the various sectors related. Because of the policy acceptance process from the government sector to the school, which must start with creating knowledge and understanding for the operators. In accordance with Phatanasiri [14], the study showed that the guidelines for school administration according to the sufficiency economy philosophy of the school must focus on clarification or the meeting of personnel to create knowledge and understanding about this philosophy. Sometimes some specialists were needed to transfer the knowledge and create awareness into the teachers. Besides, the practical as a good role model must begin from the leaders in the school, as school administrators. The results were in agreement with Singhanat [21] which mentioned that leadership was the process influencing individual and social behavior in the organization for others to follow their conceptual or needs. The leaders should be good role models, being responsible and performing appropriate behavior. Furthermore, the behaviors and practices of teachers who were close to the students, should be continuous self-development, having good attitudes and being satisfied with their work. When the school personnel comprehend obviously the clear criteria of evaluation for the activity or project, they inevitably recognized the operational goals and enable to plan the operation to achieve the objectives. In agreement with Krualao [10] who stated that apart with creating understanding for personnel in organizing activities related to the sufficiency economy philosophy, schools should promote supervision, follow-up and evaluate the activities of students' development, and should also coordinate with various sectors as the participatory management. Moreover it was consistent with Sa-ngapakpoom and others [18] who said that both the participatory management and the organizational climate were the direct positive influence on the quality of education according to the sufficiency economy philosophy. The cooperation of this process included the participation from communities and societies. In accordance with the study of Phonyiam [15] and Khunwong[8], they disclosed that the creating community cooperation and encouraging students to engage with society and communities as well as inviting people from the community to help students learn about sufficiency school, can help the implementation of the sufficiency economy philosophy successfully.

3. From the focus group discussion to determine the appropriateness of the sufficiency school operating model, the conclusion was that the participants of the focus group discussion agreed with the principles and the draft model presented by the researchers. Nevertheless, there were some suggestions for the researchers, such as entering details of sub-activities, which should be given the importance. The productive data from the researchers' collection from both questionnaires and interviews should fulfill perfection as much as possible. It was possible due to the model's elements of the operation of sufficiency school which was consistent with the sufficiency economy philosophy consisting of three cores and two conditions. In addition, there was the process driven by the quality management cycle (PDCA). It was began from planning to create understanding, implementing under the plan by acting as the role model, the evaluation of performance from the project activities as planned, and the coordination of the various sectors in the school, such as the school administrator, teachers, school personnel, students, and the others outside the school. The operation of sufficiency school must be driven by the quality management cycle (PDCA), this process was the evaluation cycle by the continuous operation which was the key to the organization's accomplishment [7]. The PDCA process can be applied to almost sections in the organization [9]. However, the sufficiency school operation was applied, combined and utilized into the five operation aspects consisting of administration aspects, curriculum aspects, activity of student development aspects, activity of personnel development aspects, and accomplishment aspects. Wherewith, the operation model of sufficiency school was derived from the study, the data collection, the synthesis both quantity and quality that rendered the model appropriately. In accordance with the research of Rarerng and Phinyo [17], the study revealed the sufficiency school administration guideline by using the sufficiency economy philosophy effectively consisted of activities operation educating to teachers, promoting teaching of sufficiency economy, activity monitoring, and public relations requests for cooperation from within the school and community. In addition, it also corresponds to Chotjirathanasak and others [4] which studied the sufficiency school administration efficiency of school under the office of the educational region 2, ministry of education. The results disclosed that the development of knowledge and morals for students and personnel in school was important, including the supervision and follow-up the school operations, the resources management, the school personnel development, participation promoting of stakeholder, the teamwork development, students' life skills development, and morals development of school personnel and students. All must be according to the sufficiency economy philosophy. Whereof the process of the sufficiency school mentioned above is in accordance with the model that the researcher had designed and developed.

\section{Suggestions}

After the researcher finished this study, there were some suggestions as follows.

This research examined only five aspects of the operation according to the King's Science in the case of sufficiency school, the next research should study as many aspects as possible. Furthermore, this research studied only the operations, in the future, there should be studies to find the solution to problems that can benefit them more. 


\section{Acknowledgements}

The authors expressed their appreciation to all school administrators and teachers who were the samplers and all experts in research methodology for their expertise and cooperation in checking research instruments, participants of the focus group discussion, a coordinator, and everyone who participated in this research.

\section{REFERENCES}

[1] Chaimee, P. Management strategies in effective sufficiency school. Panyapiwat Journal, Vol.8, No.2, 2016.

[2] Chaipattana Foundation, The origin of sufficiency economy philosophy concept, Online available from http://www.chaipat.or.th/site_content/34-13/3579-2010-10 -08-05-24-39.html

[3] Chansila, W., \& Wansri, C. Factor of learning management affected to students quality of the sufficiency economy philosophy learning center of education in northern area. Journal of Education Maha Sarakham University , Vol.12, No.3, 283-294, 2018.

[4] Chotjirathanasak, T., Wiphatakalas, C., \& Srisai, S. The administration of sufficiency schools with effectiveness under the regional education office 2. Journal of Research and Development, Valay Alongkorn Under the Royal Patronage, 57-71, 2018.

[5] Deming, W. E. Out of the Crisis, 2018.

[6] Jangsawang, W. Factors affected the behavior of the sufficiency economy philosophy in primary 6 students under the Kanchanaburi educational service area office3. Kasalong Research Journal, Vol.9, No.1, 31-42, 2015

[7] Johnson, \& N., C. The benefits of PDCA, Online available from

http://asq.org/quality-progress/2002/05/problem-solving/th e-benefits-of-pdca.html

[8] Khunwong, N. The role of school administrators in operating the school according to the sufficiency economy philosophy of Buriram primary educational service area office 3. Master's degree research, Educational administration program, Buriram Rajabhat University, 2016.

[9] Knop, K., \& Mielczarek, K. The Improvement On The Basis Of PDCA And SDCA Cycles. Quality Production Improvement, 60-71, 2015.

[10] Krualao, P. The school administration according to the sufficiency economy philosophy of Pittayalongkorn Pittayakom school. Master's degree research, Educational administration program, Silpakorn University, 2018.

[11] Ministry of Education. The handbook of sufficiency schools' assessment under the sufficiency economy philosophy. Ministry of Education, 2009.

[12] Ministry of Education. The handbook of assessment and school quality criteria, model of learning management and school administration under the sufficiency economy philosophy of basic education level. Ministry of Education, 2011.
[13] Mun Phatthana Library. King's Science...Science for sustainable development. The Book of "King of Developer" for the Benefits of All Citizens BE. 2554. Online available from http://www.manpattanalibrary.com

[14] Phatanasiri, J. The guidelines for school administration according to the sufficiency economy philosophy of schools in Nakhon Sawan Province under the office of secondary educational service area 42. Master's degree research, Educational administration program, Nakhon Sawan Rajabhat University, 2017.

[15] Phonyiam, D. Model of learning management based on the sufficiency economy philosophy in elementary schools under Roi Et primary educational service area office 3. Journal of Graduate Studies, Suan Sunandha Rajabhat University, Vol.2, No.2, 2016.

[16] Punyaban, D. 9 Following the footsteps of the King. Journal of the Society of Researchers, Vol.22, No.2, 2017.

[17] Rarerng, S., \& Phinyo, T. Administration of Sufficiency school by using the sufficiency economy philosophy under the secondary educational service area office 1 . The Proceeding of the National and International Conference, Faculty of Management Science Suan Sunandha Rajabhat University. 169-179, 2017.

[18] Sa-ngapakpoom, S., Sidakulrit, S., \& Wiangkamol, Y. The linear relationship model of factors affected the quality of education according to the sufficiency economy philosophy in schools under Office of the Basic Education Commission. Journal of Educational Administration, Khon Kaen University, Vol.13, No.1, 77-85, 2017.

[19] Saechan, P., \& Tangdamnernsawat, S. The school administration according to the sufficiency economy philosophy in schools under the office of secondary educational service area 1 Bangkok. Graduate School Journal of Suan Dusit University, Vol.14, No.2, 33-50, 2018.

[20] Sairoj, P., \& Boonrod, S. School administration in accordance with the sufficiency economy philosophy in the northern education network group under Phrae primary education service area office 1 . The Proceeding of 9th National Research Conference: Direction of Research Development in Thailand 4.0, Bureau of Research and Academic Services. Western University, 24-35, 2017.

[21] Singhanat, P. and others. The factors affected to success of school administration under the sufficiency economy philosophy of basic education level. Research Community Journal, Vol.10, No.3, 106-116, 2016.

[22] Sugarman, L. Experiential learning: Experience as the source of learning and development. Journal of Organizational Behavior, Vol.8, No.4, 359-360, 1987.

[23] Thatchai, T., Homsin, N., \& Khunakornpitak, P. Administrative factors affected the sufficiency school management under Udon Thani primary educational service areaoffice. Journal of Social Sciences Research, Vol.10, No.1, 318-337, 2019.

[24] The Secretariat of the Prime Minister. National Strategy(2018 - 1980). Government Gazette. 13 October 2018, Book 135, Episode 82A, 2018.

[25] Wattanabut, B. and others. King's science and Thai citizens development. Journal of Peace Studies, MCU, Vol.6, Special Issue, 2017.

[26] Wongthip, P. Applied community development: integration 
concept. Phra Maha Suthit Aphagaro, Editor. Learning Institute for Community (LIC), 2012.

[27] Yamane, T. Statistics: An introductory Analysis. Harper \& Row, 1973.

[28] Yuwasathirakun Foundation. The sufficiency school: education driven. Online available from http://www.sufficiencyeconomy.org/eduplan/ 